\title{
Immunomodulatory Actions of Lysophosphatidylcholine
}

\author{
Chang-Won Hong and Dong-Keun Song* \\ Department of Pharmacology, Institute of Natural Medicine, Infectious Disease Medical Research Center, \\ College of Medicine, Hallym University, Chunchon 200-702, South Korea
}

(Received May 26, 2008; Accepted June 17, 2008)

\begin{abstract}
Lysophosphatidylcholine (LPC) is an endogenous phospholipid. LPC has various stimulating or modulating activities on immune cells, including lymphocytes, monocytes/macrophages and neutrophils. Studies generally revealed pro-inflammatory activities of LPC, but accumulating evidence indicates that LPC has also anti-inflammatory actions. Here we summarize immunomodulatory actions of LPC.
\end{abstract}

Keywords: Lysophosphatidylcholine, Lymphocyte, Monocyte, Macrophage, Neutrophil

\section{INTRODUCTION}

Lysophosphatidylcholine (LPC) is an endogenous phospholipid. The concentration of LPC in plasma is very high, around 200-300 $\mu \mathrm{M}$, with most LPC bound to albumin and lipoprotein (Kishimoto et al., 2002). Because LPC is a major component of oxidized low-density lipoprotein (oxLDL), an important pathogenic factor for atherosclerosis, studies have been largely focused on LPC actions on cells involved in atherosclerosis.

Atherosclerosis is a long-standing mild inflammatory process. In addition to its effects on endothelial and smooth muscle cells, LPC has various stimulating or modulating activities on immune cells, including lymphocytes, monocytes/macrophages and neutrophils. These studies generally revealed pro-inflammatory activities of LPC, but accumulating evidence indicates that LPC has also anti-inflammatory actions, making its profile more complex than initially thought. Here we summarize immunomodulatory actions of LPC (Table I).

\section{LYMPHOCYTES}

LPC (C14:0, C16:0, C18:0, 10-50 $\mu \mathrm{M})$ greatly increases the activation of human resting $T$ lymphocytes, as measured by the expression of the $\alpha$ subunit of IL-2 receptor and thymidine uptake when co-stimulated with diacylglycerol or phorbol 12-myristate 13-acetate (PMA) plus ionomycin, a calcium ionophore, whereas LPC alone has no

\footnotetext{
${ }^{*}$ Corresponding author

Tel: +82-33-248-3290, Fax: +82-33-248-3293

E-mail: dksong@hallym.ac.kr
}

effect (Asaoka et al., 1991; Asaoka et al., 1992). LPC $(\mathrm{C} 16: 0 ; 37.5,50 \mu \mathrm{M})$ induces gene expression and secretion of heparin-binding epidermal growth factor-like growth factor (HB-EGF), a smooth muscle growth factor (Nishi et al., 1997), and enhances cytokine-induced interferon (IFN)- $\gamma$ expression (Nishi et al., 1998) in human T (CD4+ and CD8+) lymphocytes. LPC (C16:0, 1, $30 \mu \mathrm{M})$ up-regulates CD40 ligand expression in anti-CD3 antibody and CD80-stimulated human CD4+ T cells (SakataKaneko et al., 1998).

LPC (C16:0, 1-50 $\mu \mathrm{M})$ is chemoattractant for human T lymphocytes (McMurray et al., 1993; Ryborg et al., 1994). A study using a T-cell line (DO 11.10 T cell hybridoma) showed that LPC-induced chemotaxis is via G2A (Radu et al., 2004).

In addition to its chemotactic activity toward $\mathrm{T}$ cells, LPC up-regulates the expression of CXCR4, a chemokine receptor, in human CD4+ T cells (Han et al., 2004). Thus, LPC induces T cell chemotaxis to SDF-1, a ligand for CXCR4, and enhances SDF-1-induced IL-2 and IFN- $\gamma$ release from $\mathrm{CD} 4+$ cells activated by anti-CD3 antibody (Han et al., 2004).

LPC also affects B lymphocyte function; in peripheral blood mononuclear cells (PBMC), LPC (16:0, 1-25 $\mu \mathrm{M})$ increases antibody formation, most notably lgA (Huang et al., 1999).

LPC (a mixture of 16:0, 18:0 and 18:1, 5-50 $\mu \mathrm{M}$ ) increases apoptosis and reactive oxygen species (ROS) generation in phytohemagglutinin (PHA)-activated but not in control human peripheral blood lymphocytes (Zurgil et al., 2007).

LPC $(20-45 \mu \mathrm{g} / \mathrm{ml})$ induces p56 ${ }^{\text {lck }}$ and ZAP ${ }^{70}$ phosphorylation, and increases $\left[\mathrm{Ca}^{2+}\right]_{i}$ in Jurkat cells, a cell line for 
Table I. Some important actions of lysohosphatidylcholine on lymphocyte, monocyte/macrophage, and neutrophil

\section{Lymphocyte}

Chemoattractant (McMurray et al., 1993; Ryborg et al., 1994; Radu et al., 2004)

IL-2R $\alpha \uparrow /$ thymidine uptake $\uparrow$ (Asaoka et al., 1991; Asaoka et al., 1992)

HB-EGF $\uparrow$ (Nishi et al., 1997), IFN- $\gamma \uparrow$ (Nishi et al., 1998)

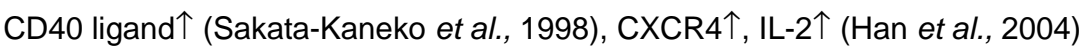

Antibody formation $\uparrow$, most notably $\lg A$ (Huang et al., 1999)

Apoptosis $\uparrow / R O S$ generation $\uparrow$ (Zurgil et al., 2007)

p56 ${ }^{\text {lck }}$ and ZAP ${ }^{70}$ phosphorylation $\uparrow,[\mathrm{Ca} 2+]_{\mathrm{i}} \uparrow$ in Jurkat cells (Legradi et al., 2004)

\section{Monocyte/macrophage}

Chemoattractant (Quinn et al., 1988)

Activates p38 and p42/44 MAPKs in THP-1 cells (Jing et al., 2000)

Mitogenic effects of acetylated LDL $\uparrow$ (Sakai et al., 1994)

Mature dendritic cell generation $\uparrow / C D 86 \uparrow$ (Coutant et al., 2002)

Adhesion $\uparrow /$ activation of CD11b (Weber et al., 1995)

IFN- $\gamma \uparrow$ (Nakano et al., 1994), IL-1 $\beta \uparrow$ (Liu-Wu et al., 1998), TNF- $\alpha \uparrow$ (Huang et al., 1999), MIP2 $\uparrow$ in RAW264.7 cells

(Olofsson et al., 2008), arachidonic acid $\uparrow$ in THP-1 and Mono Mac6 cells (Oestvang et al., 2003)

Phospholipase D (PLD) activity $\uparrow$ (Gómez-Muñoz et al., 1999)

Extracellular acidification $\uparrow$ in RAW264.7 cells (De Vries et al., 1998)

EC-SOD $\uparrow$ in U937 cells (Yamamoto et al., 2002)

$\mathrm{Ca}^{2+}$ influx $\uparrow$ in U937 human monocytes (Yun et al., 2004)

De-ramification of murine microglia $\uparrow /$ nonselective cation current $\uparrow$, calcium-activated potassium current $\uparrow /$ hyperpolarization $\uparrow$ (Schilling et al., 2004)

\section{Neutrophil}

Synergistically enhances PMA-induced superoxide anion generation (Englberger et al., 1987)

Generation from stored blood (Silliman et al., 1994; Silliman et al., 1996)

Superoxide anion generation is inhibited with PI3K inhibitors (Nishioka et al., 1998)

$\mathrm{H}_{2} \mathrm{O}_{2}$ generation/bactericidal activity in a G2A-dependent manner (Yan et al., 2004)

Priming of NADPH oxidase is dependent on $\left[\mathrm{Ca}^{2+}\right]_{i}$ increase (Silliman et al., 2003)

Apoptosis $\downarrow$ (Biffl et al., 2003)

$\left[\mathrm{Ca}^{2+}\right]_{\mathrm{i}} \uparrow$ via G2A/mobilization of G2A along with secretory vesicles (Frasch et al., 2007)

$\left[\mathrm{Ca}^{2+}\right]_{\mathrm{i}} \uparrow$ via PLC in HL60 cells (Okajima et al., 1998)

human CD4+ T lymphocytes (Legradi et al., 2004). The $\mathrm{LPC}$-induced $\left[\mathrm{Ca}^{2+}\right]_{\mathrm{i}}$ level is blocked by pertussis toxin (PTX), a Gi blocker, genistein, a tyrosine kinase inhibitor and staurosporine, a PKC inhibitor. In S49 lymphoma cells, LPC (C16:0, 2-25 $\mu \mathrm{M})$-induced $\mathrm{Ca}^{2+}$ increase by formation of transient non-protein calcium pores was reported (Wilson-Ashworth et al., 2004).

\section{MONOCYTES/MACROPHAGES}

LPC $(16: 0,25 \mu \mathrm{M})$ induces chemotaxis of human monocytes (Quinn et al., 1988). As for T lymphocytes,
LPC-mediated chemotaxis of macrophages is mediated via G2A, shown in mouse peritoneal macrophages and J774A.1 macrophages (Yang et al., 2005). Interestingly, unlike other chemoattractants which are dependent on Gi proteins, G2A-mediated macrophage chemotaxis uses $\mathrm{Gq} / 11$ and G12/13 (Yang et al., 2005). However, in G2A ${ }^{-/}$ mice, infiltration of macrophages and $T$ lymphocytes was not reduced in atherosclerotic lesion (Parks et al., 2005).

LPC released by apoptotic cells is a phagocyte attraction signal; LPC $(10-20 \mu \mathrm{M})$ was chemotactic to THP-1 and mono Mac 1 cells (Lauber et al., 2003). In studies using U937 (G2A transfected), THP-1, and mouse J774A.1 
macrophages, chemotaxis of these cells to LPC is mediated by G2A (Peter et al., 2008).

In THP-1 cells, LPC $(25 \mu \mathrm{g} / \mathrm{ml})$ activates p38 and p42/ 44 mitogen-activated protein kinases (MAPKs) but only p38 activation is involved in stimulated chemotaxis (Jing et al., 2000). LPC-induced p38 phosphorylation is blocked by PTX, and inhibited by a phospholipase $C$ inhibitor (U73122) and phosphatidylinositol 3-kinase (PI3K) inhibitors (wortmannin and LY294002).

LPC (C16:0, C18:0, C18:1, $50 \mu \mathrm{M})$ markedly enhances mitogenic effects of acetylated LDL on murine resident macrophages, whereas LPC alone has no effect (Sakai et al., 1994).

LPC $(40 \mu \mathrm{M})$ promotes mature dendritic cell generation from differentiating monocytes with up-regulation of CD86. LPC-induced CD86 up-regulation is inhibited by platelet activating factor receptor (PAFR) antagonist, BN52021, and PTX (Coutant et al., 2002). LPC-treated mature dendritic cells induce a Th1-biased response, partly via the peroxisome proliferator-activated receptors (PPAR) signaling (Coutant et al., 2004).

LPC increases adhesion of human peripheral blood monocytes. This effect is mediated by activation of CD11b via protein kinase C (PKC) signaling (Weber et al., 1995).

As the case for T lymphocytes (Nishi et al., 1997), LPC (C18:0, 25 and $37.5 \mu \mathrm{g} / \mathrm{ml}$ ) increases the expression of HB-EGF in human monocytes (Nakano et al., 1994). LPC $(\mathrm{C} 16: 0,25,30 \mu \mathrm{M})$ induces the production of IL-1 $\beta$ in human monocytes (Liu-Wu et al., 1998) and in mouse peritoneal macrophages (Yan et al., 2004). LPC (C16:0, 5 $\mu \mathrm{M})$ induces the production of IFN- $\gamma$ and tumor necrosis factor (TNF)- $\alpha$ from human PBMC (Huang et al., 1999). This response is inhibited by WEB 2170, a PAFR antagonist (Huang et al., 1999). LPC induces increased release of macrophage-inflammatory protein-2 (MIP2) and mRNA expression from RAW264.7 cells (Olofsson et al., 2008).

LPC itself is a product of phospholipase A2 $\left(\mathrm{PLA}_{2}\right)$. However, intriguingly, LPC (C16:0, $40 \mu \mathrm{M})$ induces arachidonic acid release from THP-1 and Mono Mac6 cells via secretary $\mathrm{PLA}_{2}$ and cytosolic $\mathrm{PLA}_{2}$ signal in a PTXdependent manner (Oestvang et al., 2003), suggesting that LPC somehow stimulates PLA ${ }_{2}$, forming a positive feedback for generation of LPC. LPC $(1 \mu \mathrm{g} / \mathrm{ml})$ increases phospholipase $D$ (PLD) activity in mouse peritoneal macrophages. This effect was inhibited by down-regulation of PKC activity (with prolonged incubation with PMA), or inhibitors of tyrosine kinase (genistein) and PAFR (WEB2086) (Gómez-Muñoz et al., 1999). Because PLD activity produces phosphatidic acid which can activate $\mathrm{PLA}_{2}$ (Bauldry et al., 1997), PLD could be involved in LPC- induced release of arachidonic acid from THP-1 and Mono Mac6 cells (Oestvang et al., 2003).

LPC (10-100 $\mu \mathrm{M})$ increases extracellular acidification in RAW264.7 cells (De Vries et al., 1998). LPC (10-30 $\mu \mathrm{g} / \mathrm{ml})$ increases extracellular-superoxide dismutase (EC-SOD) expression and release from human monocytic U937 cells (Yamamoto et al., 2002). In U937 cells, LPC (C14:0, $20 \mu \mathrm{M}$ ) did not induce significant $\mathrm{Ca}^{2+}$ influx (Lee et al., 2004), but LPC (C16:0, C18:0, $10 \mu \mathrm{M})$ induced $\mathrm{Ca}^{2+}$ influx in U937 human monocytes in a PTX-insensitive manner (Yun et al., 2004). In the subsequent study, LPC (C16:0, $10 \mu \mathrm{M}$ )-induced $\mathrm{Ca}^{2+}$ influx was suggested to be via $\mathrm{L}-$ type calcium channel, as it was inhibited by verapamil $(100 \mu \mathrm{M})$ and nifedifine $(100 \mu \mathrm{M})$ (Lee et al., 2006).

LPC $(C 16: 0,15 \mu \mathrm{M})$ induces de-ramification of murine microglia, and nonselective cation current, and calciumactivated potassium current, with the subsequent hyperpolarization (Schilling et al., 2004)

\section{NEUTROPHILS}

LPC $(1 \mu \mathrm{M})$ alone slightly increases superoxide anion generation, and when co-treated with PMA, synergistically enhances PMA-induced superoxide anion generation (Englberger et al., 1987). Subsequent study showed that LPCs having fatty acids with more than 10 carbons enhance superoxide responses of stimulated human neutrophils (Ginsburg et al., 1989; Wyman et al., 2002). Lipids generated from stored blood were found to prime neutrophils, and identified to be LPCs (Silliman et al., 1994; Silliman et al., 1996).

LPC (C16:0, 5-15 $\mu \mathrm{M})$-induced superoxide anion generation is inhibited with PI3K inhibitors (wortmannin and LY294002), but not by PKC inhibitors (GF109203X and calphostin C) (Nishioka et al., 1998). LPC (18:0, $30 \mu \mathrm{M})$ induces $\mathrm{H}_{2} \mathrm{O}_{2}$ generation and enhances bactericidal activity in murine neutrophils in a G2A-dependent manner (Yan et al., 2004).

LPC-induced changes in human neutrophils were extensively studied by Silliman et al. (2003). In addition to priming formyl-Met-Leu-Phe (fMLP)-induced activation of the reduced nicotinamide adenine dinucleotide phosphate (NADPH) oxidase, LPC (0.45-14.5 $\mu \mathrm{M})$ enhances adhesion of neutrophils to fibrinogen-coated microtiter plates and surface expression of the CD11b and fMLP receptor (Silliman et al., 2003). LPC $(0.45$ and $4.5 \mu \mathrm{M})$ increases $\left[\mathrm{Ca}^{2+}\right]_{i}$ via PTX-sensitive manner, and migration of neutrophils in a Boyden chamber (Silliman et al., 2003). LPC $(4.5 \mu \mathrm{M})$ modestly increases release of elastase, myeloperoxidase, and lactoferrin (Silliman et al., 2003). 
All the above effects of LPC were blocked by chelating cytosolic calcium (Silliman et al., 2003). LPC $(4.5 \mu \mathrm{M})$ delays neutrophil apoptosis (Biffl et al., 2003). LPC (C18:1, $10 \mu \mathrm{M})$ increases $\left[\mathrm{Ca}^{2+}\right]_{i}$ in neutrophils via $\mathrm{G} 2 \mathrm{~A}$, and induces mobilization of G2A along with secretory vesicles (Frasch et al., 2007).

In HL60 leukemic cells, LPC (C16:0, $30 \mu \mathrm{M})$ increases $\left[\mathrm{Ca}^{2+}\right]_{i}$ by stimulation of PLC in a PTX-sensitive manner, whereas LPC $(\mathrm{C} 18: 0,30 \mu \mathrm{M})$, which per se very slightly increases $\left[\mathrm{Ca}^{2+}\right]_{i}$, inhibits the effect of LPC (C16:0, 30 $\mu \mathrm{M})$ (Okajima et al., 1998). In the same cell line, a slight discrepancy was reported in that LPC $(\mathrm{C} 18: 0,10 \mu \mathrm{M})$ and $\mathrm{LPC}(\mathrm{C} 16: 0,10 \mu \mathrm{M})$ show equipotent activity regarding $\left[\mathrm{Ca}^{2+}\right]_{\mathrm{i}}$ increase, although the onset of $\left[\mathrm{Ca}^{2+}\right]_{\mathrm{i}}$ increase induced by LPC $(\mathrm{C} 18: 0,10 \mu \mathrm{M})$ is slower than LPC (C16:0, $10 \mu \mathrm{M}$ )-induced one (Lee et al., 2004).

For eosinohils, enhanced eosinophil adhesion by LPC via a non-store-operated $\mathrm{Ca}^{2+}$ influx leading to $\mathrm{CD} 11 \mathrm{~b} /$ CD18 activation was reported (Zhu et al., 2007).

\section{LPC concentrations}

Most studies on LPC were conducted with LPC concentrations of around 1-50 $\mu \mathrm{M}$. Recently, nanomolar LPC was shown to induce THP-1 monocyte chemotaxis (Olofsson et al., 2008).

Because LPC avidly binds to albumin and lipoproteins, LPC activities are varied in different medium conditions, including the presence and the amount of albumin and serum in the medium. Therefore, not knowing the concentration of free LPC, comparison between data from different papers based only on the LPC concentrations used may be difficult to interpret.

\section{Priming}

One of characteristics of LPC actions is that LPC per $s e$ is a weak stimulator or even inactive, however, when LPC is combined with other stimulators, synergistic interactions often occurs (Englberger et al., 1987; Ginsburg et al., 1989; Asaoka et al., 1991; Asaoka et al., 1992; Sakai et al., 1994; Wyman et al., 2002). The most prominent example is seen in the priming of respiratory burst of neutrophils. This LPC-induced priming was clearly shown to be due to the LPC-induced $\left[\mathrm{Ca}^{2+}\right]_{\text {i }}$ increase (Silliman et al., 2003). LPC also increases $\left[\mathrm{Ca}^{2+}\right]_{i}$ in other types of immune cells (Legradi et al., 2004; Wilson-Ashworth et al., 2004). This LPC-induced $\left[\mathrm{Ca}^{2+}\right]_{i}$ increase most probably underlie the synergistic interactions between LPC and other stimulators observed also in other cells, including lymphocytes, and monocytes/macrophages (Asaoka et al., 1991; Asaoka et al., 1992; Sakai et al., 1994; Schill- ing et al., 2004; Yun et al., 2004).

\section{Anti-inflammatory actions of LPC}

Although a number of papers demonstrated the proinflammatory actions of LPC, accumulating evidence shows that LPC has also anti-inflammatory profiles.

Systemic administration of LPC (18:0; $10 \mathrm{mg} / \mathrm{kg}$ s.c., four times every $12 \mathrm{~h}$ ) to mice protected LPS-induced lethality, and inhibited LPS-induced increased in plasma levels of TNF- $\alpha$ and IL-1 $\beta$ (Yan et al., 2004). In vitro, LPC inhibited basal and LPS-induced TNF- $\alpha$ release from neutrophils (Yan et al., 2004). LPC administration inhibited LPS- or CLP-induced increase in plasma HMGB1 levels, and LPC inhibited high-mobility group box 1 (HMGB1) release from macrophages or monocytes (Chen et al., 2005). Furthermore, LPC administration inhibited LPS- or peptidoglycan/lipoteichoic acid-induced multiple organ damage in rats (Murch et al., 2006).

Several studies have shown that LPC can inhibit some lipopolysaccharide (LPS) actions. LPC (1-10 $\mu \mathrm{M})$ inhibits LPS-induced tissue factor (TF) activity and mRNA expression from human monocytes (Engelmann et al., 1999). LPC increases cAMP levels in monocytes (Engelmann et al., 1999) and THP-1 cells (Yuan et al., 1996).

LPC (C16:0) inhibits PMA- or PMLP-stimulated ROS in neutrophils (Müller et al., 2002). Further, fMLP-induced ROS and other fMLP-induced signaling in neutrophils, as well as lung injury induced by fMLP-stimulated neutrophils were inhibited by LPC $(0.1,1 \mu \mathrm{M})$ treatment through elevation of cAMP (Lin et al., 2005). In HL60 leukemic cells, an inhibitory effect of LPC (C18:0) on stimulated PLC- $\left[\mathrm{Ca}^{2+}\right]_{i}$ signal was reported (Okajima et al., 1998).

Because CAMP-PKA system negatively regulates inflammatory processes in immune cells, LPC-induced increase in CAMP (most probably via GPCR-Gs protein signaling) may underlie, at lest in part, some of the negative regulatory actions cited above.

In a similar vein, LPC $(10 \mu \mathrm{g} / \mathrm{ml})$ increases expression and release of EC-SOD, a protecting factor against atherogenesis, from human monocytic U937 cells (Yamamoto et al., 2002), possibly negating, to some extent, the pro-atherogenic effects of LPC.

\section{LPC/PC ratio}

Lysophosphatidylcholine acyltransferase (LPCAT) acylates LPC to phosphatidylcholine (PC), making LPC/PC ratio in the plasma to decrease. LPCAT inhibition (thus increasing LPC/PC ratio) inhibits LPS signaling (Schmid et al., 2003). LPCAT inhibition (thus increasing LPC/PC ratio) prevents translocation of Toll-like receptor (TLR)-4, 
the receptor for LPS, to lipid raft domain (Jackson et al., 2008), supplying additional plausible evidence to explain the previous data of LPC inhibition of LPS signal.

In line with this contention, plasma levels of LPC are decreased in septic patients, and the decrease is greater in non-survivals (Drobnik et al., 2003), suggesting the possibility that depletion of LPC may aggravate inflammatory process. Further supporting this notion, plasma levels of LPC are correlated inversely with inflammatory parameters, such as plasma C-reactive protein and whole blood hydrogen peroxide levels in cancer patients (Taylor et al., 2007).

\section{Receptors}

G2A is expressed in lymphocytes (Weng et al., 1998), macrophages (Rikitake et al., 2002), and neutrophils (Yan et al., 2004), but not U937 human monocytes (Yun et al., 2004). A number of LPC actions, but not all, are blocked by either anti-G2A antibody or silencing of G2A (Han et al., 2004; Radu et al., 2004; Frasch et al., 2007; Peter et al., 2008). Therefore, G2A is regarded as an effector of LPC in some systems. Recently, LPC-induced mobilization of G2A located in the secretary vesicles to plasma membrane was proposed as a mechanism for LPC modulation of G2A (Frasch et al., 2007).

Many actions of LPC were blocked or inhibited by PAFR antagonists (Ogita et al., 1997; Gómez-Muñoz et al., 1999; Coutant et al., 2002). However, no studies were conducted so far regarding the precise molecular interactions between LPC and PAF receptor signaling. It is to be noted that all such data were from antagonist studies, and no genetic data are available on the involvement of PAFR in LPC actions. Interestingly, WEB 2170, one of the most widely used PAFR antagonist, partially inhibited LPCinduced priming, but WEB 2347, a highly selective PAFR antagonist had no effect (Silliman et al., 2003). Furthermore, WEB 2170 also inhibited leukotriene $\mathrm{B}_{4}\left(\mathrm{LTB}_{4}\right)$ - and oleoyl-acetylglycerol (OAG)-induce priming of fMLP-activated respiratory burst (Silliman et al., 2003). Immune cells with knock-downed PAFR would be useful to prove more definitely the interaction of LPC with PAFR signaling.

\section{G proteins}

Studies indicate the involvement of $\mathrm{Gi}, \mathrm{Gs}, \mathrm{Gq}$ and G12/13 in LPC actions in immune cells. Many actions of LPC are blocked or inhibited by PTX, a Gi blocker (Huang et al., 1999; Jing et al., 2000; Coutant et al., 2002; Oestvang et al., 2003; Silliman et al., 2003; Legradi et al., 2004; Yun et al., 2004; Yang et al., 2005). LPC increased cAMP levels in monocytes (Engelmann et al.,
1999), THP-1 cells (Yuan et al., 1996), and neutrophils (Lin et al., 2005), indicating the involvement of Gs protein in LPC action in immune cells. Notably, G2A-dependent chemotaxis of macrophages is dependent on $\mathrm{Gq}$ and G12/13 (Yang et al., 2005).

\section{In vivo immuno-modulatory actions of LPC}

Compared to in vitro data, in vivo data of immuno-modulatory actions of LPC is relatively scant. Treatment of mice with LPC induces enhanced phagocytic activity of macrophages (Ngwenya et al., 1985). Vitamin $D_{3}$-binding protein was reported to play an important role in this response (Yamamoto et al., 1996). Micro-injection of LPC into the spinal cord induces increased recruitment of immune cells, including T cells, neutrophils, and Mac-1+ monocyte (Ousman et al., 2000). Intracutaneous injection of LPC in healthy volunteers similarly elicited acute inflammation with the accumulation of $T$ lymphocytes, monocytes and neutrophils (Ryborg et al., 2000).

Systemic administration of LPC (C18:0; $10 \mathrm{mg} / \mathrm{kg}$ s.C., four times every $12 \mathrm{~h}$ ) protected mice against experimental sepsis-induced lethality, enhanced bacterial clearance and inhibited experimental sepsis-induced increase in TNF- $\alpha$ and IL-1 $\beta$, and enhanced IFN- $\gamma$ and IL-2 levels (Yan et al., 2004). LPC administration inhibited LPS- or cecal ligation and puncture (CLP)-induced increase in plasma HMGB1 levels in mice (Chen et al., 2005). Furthermore, LPC administration inhibited LPS- or peptidoglycan/lipoteichoic acid-induced multiple organ damage in rats (Murch et al., 2006).

When injected in hind footpads with protein antigen, LPC was found to act as an adjuvant initiating both humoral and cellular immune responses with an efficiency nearly equal to alum, the standard adjuvant for immunization (Perrin-Cocon et al., 2006).

\section{CONCLUSION}

As a major lysophospholipid in the body, LPC having both the pro-inflammatory and anti-inflammatory actions may be more suitable for maintaining homeostasis of the body. Thus, looking at both sides of actions would bring more realistic view of the roles that LPC plays in the biological systems.

\section{ACKNOWLEDGEMENTS}

This work was supported by the Korea Science and Engineering MRC program of MOST/KOSEF (grant: R13-2005-022-01000-0). 


\section{REFERENCES}

Asaoka, Y., Oka, M., Yoshida, K. and Nishizuka, Y. (1991). Lysophosphatidylcholine as a possible second messenger synergistic to diacylglycerol and calcium ion for T-lymphocyte activation. Biochem Biophys Res Commun. 178(3), 13781385.

Asaoka, Y., Oka, M., Yoshida, K., Sasaki, Y. and Nishizuka, Y. (1992). Role of lysophosphatidylcholine in T-lymphocyte activation: involvement of phospholipase A2 in signal transduction through protein kinase C. Proc Natl Acad Sci USA. 89(14), 6447-6451.

Bauldry, S. A. and Wooten, R. E. (1997). Induction of cytosolic phospholipase A2 activity by phosphatidic acid and diglycerides in permeabilized human neutrophils: interrelationship between phospholipases D and A2. Biochem J. 322 (Pt 2), 353-363.

Biffl, W. L., Carnaggio, R., Moore, E. E., Ciesla, D. J., Johnson, J. L. and Silliman, C. C. (2003). Clinically relevant hypertonicity prevents stored blood- and lipid-mediated delayed neutrophil apoptosis independent of p38 MAPK or caspase-3 activation. Surgery. 134(1), 86-91.

Chen, G., Li, J., Qiang, X., Czura, C. J., Ochani, M., Ochani, K., Ulloa, L., Yang, H., Tracey, K. J., Wang, P., Sama, A. E. and Wang, H. (2005). Suppression of HMGB1 release by stearoyl lysophosphatidylcholine:an additional mechanism for its therapeutic effects in experimental sepsis. J Lipid Res. 46(4), 623-627.

Coutant, F., Agaugué, S., Perrin-Cocon, L., André, P. and Lotteau, V. (2004). Sensing environmental lipids by dendritic cell modulates its function. J Immunol. 172(1), 54-60.

Coutant, F., Perrin-Cocon, L., Agaugué, S., Delair, T., André, P. and Lotteau, V. (2002). Mature dendritic cell generation promoted by lysophosphatidylcholine. J Immunol. 169(4), 16881695.

De Vries, H. E., Ronken, E., Reinders, J. H., Buchner, B., Van Berkel, T. J. and Kuiper, J. (1998). Acute effects of oxidized low density lipoprotein on metabolic responses in macrophages. FASEB J. 12(1), 111-118.

Drobnik, W., Liebisch, G., Audebert, F. X., Frohlich, D., Gluck, T., Vogel, P., Rothe, G. and Schmitz, G. (2003). Plasma ceramide and lysophosphatidylcholine inversely correlate with mortality in sepsis patients. J Lipid Res. 44(4), 754-761.

Engelmann, B., Zieseniss, S., Brand, K., Page, S., Lentschat, A., Ulmer, A. J. and Gerlach, E. (1999). Tissue factor expression of human monocytes is suppressed by lysophosphatidylcholine. Arterioscler Thromb Vasc Biol. 19(1), 47-53.

Englberger, W., Bitter-Suermann, D. and Hadding, U. (1987). Influence of lysophospholipids and PAF on the oxidative burst of PMNL. Int J Immunopharmacol. 9(3), 275-282.

Frasch, S. C., Zemski-Berry, K., Murphy, R. C., Borregaard, N., Henson, P. M. and Bratton, D. L. (2007). Lysophospholipids of different classes mobilize neutrophil secretory vesicles and induce redundant signaling through G2A. J Immunol. 178(10), 6540-6548.

Ginsburg, I., Ward, P. A. and Varani, J. (1989). Lysophosphatides enhance superoxide responses of stimulated human neutrophils. Inflammation. 13(2), 163-174.
Gómez-Muñoz, A., O'Brien, L., Hundal, R. and Steinbrecher, U. P. (1999). Lysophosphatidylcholine stimulates phospholipase $\mathrm{D}$ activity in mouse peritoneal macrophages. $J$ Lipid Res. 40(6), 988-993.

Han, K. H., Hong, K. H., Ko, J., Rhee, K. S., Hong, M. K., Kim, J. J., Kim, Y. H. and Park, S. J. (2004). Lysophosphatidylcholine up-regulates CXCR4 chemokine receptor expression in human CD4 T cells. Journal of Leukocyte Biology. 76(1), 195202.

Huang, Y. H., Schafer-Elinder, L., Wu, R., Claesson, H. E. and Frostegard, J. (1999). Lysophosphatidylcholine (LPC) induces proinflammatory cytokines by a platelet-activating factor (PAF) receptor-dependent mechanism. Clin Exp Immunol. 116(2), 326-331.

Jackson, S. K., Abate, W., Parton, J., Jones, S. and Harwood, J. L. (2008). Lysophospholipid metabolism facilitates Toll-like receptor 4 membrane translocation to regulate the inflammatory response. Journal of Leukocyte Biology.

Jing, Q., Xin, S. M., Zhang, W. B., Wang, P., Qin, Y. W. and Pei, G. (2000). Lysophosphatidylcholine activates p38 and p42/44 mitogen-activated protein kinases in monocytic THP-1 cells, but only p38 activation is involved in its stimulated chemotaxis. Circ Res. 87(1), 52-59.

Kishimoto, T., Soda, Y., Matsuyama, Y. and Mizuno, K. (2002). An enzymatic assay for lysophosphatidylcholine concentration in human serum and plasma. Clin Biochem. 35(5), 411416.

Lauber, K., Bohn, E., Krober, S. M., Xiao, Y. J., Blumenthal, S. G. Lindemann, R. K., Marini, P., Wiedig, C., Zobywalski, A., Baksh, S., Xu, Y., Autenrieth, I. B., Schulze-Osthoff, K., Belka, C., Stuhler, G and Wesselborg, S. (2003). Apoptotic cells induce migration of phagocytes via caspase-3-mediated release of a lipid attraction signal. Cell. 113(6), 717-730.

Lee, H. Y., Kang, H. K., Yoon, H. R., Kwak, J. Y. and Bae, Y. S. (2004). Lysophosphatidic acid is a mediator of Trp-Lys-TyrMet-Val-d-Met-induced calcium influx. Biochem Biophys Res Commun. 324(1), 458-465.

Lee, Y. K., Im, Y. J., Kim, Y. L. and Im, D. S. (2006). Characterization of $\mathrm{Ca2}+$ influx induced by dimethylphytosphingosine and lysophosphatidylcholine in U937 monocytes. Biochem Biophys Res Commun. 348(3), 1116-1122.

Legradi, A., Chitu, V., Szukacsov, V., Fajka-Boja, R., Szekely Szucs, K. and Monostori, E. (2004). Lysophosphatidylcholine is a regulator of tyrosine kinase activity and intracellular $\mathrm{Ca}(2+)$ level in Jurkat T cell line. Immunol Lett. 91(1), 17-21.

Lin, P., Welch, E. J., Gao, X. P., Malik, A. B. and Ye, R. D. (2005). Lysophosphatidylcholine modulates neutrophil oxidant production through elevation of cyclic AMP. J Immunol. 174(5), 2981-2989.

Liu-Wu, Y., Hurt-Camejo, E. and Wiklund, O. (1998). Lysophosphatidylcholine induces the production of $\mathrm{IL}-1 \beta$ by human monocytes. Atherosclerosis. 137(2), 351-357.

McMurray, H. F., Parthasarathy, S. and Steinberg, D. (1993). Oxidatively modified low density lipoprotein is a chemoattractant for human T lymphocytes. J Clin Invest. 92(2), 10041008.

Müller, J., Petkovi, M., Schiller, J., Arnold, K., Reichl, S. and Arnhold, J. (2002). Effects of lysophospholipids on the genera- 
tion of reactive oxygen species by fMLP- and PMA-stimulated human neutrophils. Luminescence : the journal of biological and chemical luminescence. 17(3), 141-149.

Murch, O., Collin, M., Sepodes, B., Foster, S. J., Mota-Filipe, H. and Thiemermann, C. (2006). Lysophosphatidylcholine reduces the organ injury and dysfunction in rodent models of gramnegative and gram-positive shock. Br J Pharmacol. 148(6), 769-777.

Nakano, T., Raines, E. W., Abraham, J. A., Klagsbrun, M. and Ross, R. (1994). Lysophosphatidylcholine upregulates the level of heparin-binding epidermal growth factor-like growth factor mRNA in human monocytes. Proc Natl Acad Sci USA. 91(3), 1069-1073.

Ngwenya, B. Z. and Yamamoto, N. (1985). Activation of peritoneal macrophages by lysophosphatidylcholine. Biochim Biophys Acta. 839(1), 9-15.

Nishi, E., Kume, N., Ochi, H., Moriwaki, H., Wakatsuki, Y., Higashiyama, S., Taniguchi, N. and Kita, T. (1997). Lysophosphatidylcholine increases expression of heparin-binding epidermal growth factor-like growth factor in human T lymphocytes. Circ Res. 80(5), 638-644.

Nishi, E., Kume, N., Ueno, Y., Ochi, H., Moriwaki, H. and Kita, T. (1998). Lysophosphatidylcholine enhances cytokine-induced interferon gamma expression in human T lymphocytes. Circ Res. 83(5), 508-515.

Nishioka, H., Horiuchi, H., Arai, H. and Kita, T. (1998). Lysophosphatidylcholine generates superoxide anions through activation of phosphatidylinositol 3-kinase in human neutrophils. FEBS Lett. 441(1), 63-66.

Oestvang, J., Anthonsen, M. W. and Johansen, B. (2003). Role of secretory and cytosolic phospholipase $A(2)$ enzymes in lysophosphatidylcholine-stimulated monocyte arachidonic acid release. FEBS Lett. 555(2), 257-262.

Ogita, T., Tanaka, Y., Nakaoka, T., Matsuoka, R., Kira, Y., Nakamura, M., Shimizu, T. and Fujita, T. (1997). Lysophosphatidylcholine transduces $\mathrm{Ca} 2+$ signaling via the platelet-activating factor receptor in macrophages. Am J Physiol. 272(1 Pt 2), H17-24.

Okajima, F., Sato, K., Tomura, H., Kuwabara, A., Nochi, H., Tamoto, K., Kondo, Y., Tokumitsu, Y. and Ui, M. (1998). Stimulatory and inhibitory actions of lysophosphatidylcholine, depending on its fatty acid residue, on the phospholipase C/ Ca2+ system in HL-60 leukaemia cells. Biochem J. 336 (Pt 2), 491-500.

Olofsson, K. E., Andersson, L., Nilsson, J. and Björkbacka, H. (2008). Nanomolar concentrations of lysophosphatidylcholine recruit monocytes and induce pro-inflammatory cytokine production in macrophages. Biochem Biophys Res Commun. 370(2), 348-352.

Ousman, S. S. and David, S. (2000). Lysophosphatidylcholine induces rapid recruitment and activation of macrophages in the adult mouse spinal cord. Glia. 30(1), 92-104.

Parks, B. W., Gambill, G. P., Lusis, A. J. and Kabarowski, J. H. (2005). Loss of G2A promotes macrophage accumulation in atherosclerotic lesions of low density lipoprotein receptor-deficient mice. J Lipid Res. 46(7), 1405-1415.

Perrin-Cocon, L., Agaugue, S., Coutant, F., Saint-Mezard, P., Guironnet-Paquet, A., Nicolas, J. F., Andre, P. and Lotteau, V.
(2006). Lysophosphatidylcholine is a natural adjuvant that initiates cellular immune responses. Vaccine. 24(9), 1254-1263.

Peter, C., Waibel, M., Radu, C. G., Yang, L. V., Witte, O. N., Schulze-Osthoff, K., Wesselborg, S. and Lauber, K. (2008). Migration to apoptotic "find-me" signals is mediated via the phagocyte receptor G2A. J Biol Chem. 283(9), 5296-5305.

Quinn, M. T., Parthasarathy, S. and Steinberg, D. (1988). Lysophosphatidylcholine: a chemotactic factor for human monocytes and its potential role in atherogenesis. Proc Natl Acad Sci U S A. 85(8), 2805-2809.

Radu, C. G., Yang, L. V., Riedinger, M., Au, M. and Witte, O. N. (2004). T cell chemotaxis to lysophosphatidylcholine through the G2A receptor. Proc Natl Acad Sci U S A. 101(1), 245250.

Rikitake, Y., Hirata, K., Yamashita, T., Iwai, K., Kobayashi, S., Itoh, H., Ozaki, M., Ejiri, J., Shiomi, M., Inoue, N., Kawashima, S. and Yokoyama, M. (2002). Expression of G2A, a receptor for lysophosphatidylcholine, by macrophages in murine, rabbit, and human atherosclerotic plaques. Arterioscler Thromb Vasc Biol. 22(12), 2049-2053.

Ryborg, A. K., Deleuran, B., Sogaard, H. and Kragballe, K. (2000). Intracutaneous injection of lysophosphatidylcholine induces skin inflammation and accumulation of leukocytes. Acta Derm Venereol. 80(4), 242-246.

Ryborg, A. K., Deleuran, B., Thestrup-Pedersen, K. and Kragballe, K. (1994). Lysophosphatidylcholine: a chemoattractant to human T lymphocytes. Arch Dermatol Res. 286(8), 462465.

Sakai, M., Miyazaki, A., Hakamata, H., Sasaki, T., Yui, S., Yamazaki, M., Shichiri, M. and Horiuchi, S. (1994). Lysophosphatidylcholine plays an essential role in the mitogenic effect of oxidized low density lipoprotein on murine macrophages. $J$ Biol Chem. 269(50), 31430-31435.

Sakata-Kaneko, S., Wakatsuki, Y., Usui, T., Matsunaga, Y., Itoh, T., Nishi, E., Kume, N. and Kita, T. (1998). Lysophosphatidylcholine upregulates CD40 ligand expression in newly activated human CD4+ T cells. FEBS Lett. 433(1-2), 161-165.

Schilling, T., Lehmann, F., Rückert, B. and Eder, C. (2004). Physiological mechanisms of lysophosphatidylcholine-induced de-ramification of murine microglia. J Physiol (Lond). 557(Pt 1), 105-120.

Schmid, B., Finnen, M. J., Harwood, J. L. and Jackson, S. K. (2003). Acylation of lysophosphatidylcholine plays a key role in the response of monocytes to lipopolysaccharide. Eur $J$ Biochem. 270(13), 2782-2788.

Silliman, C. C., Clay, K. L., Thurman, G. W., Johnson, C. A. and Ambruso, D. R. (1994). Partial characterization of lipids that develop during the routine storage of blood and prime the neutrophil NADPH oxidase. J Lab Clin Med. 124(5), 684-694.

Silliman, C. C., Dickey, W. O., Paterson, A. J., Thurman, G. W., Clay, K. L., Johnson, C. A. and Ambruso, D. R. (1996). Analysis of the priming activity of lipids generated during routine storage of platelet concentrates. Transfusion. 36(2), 133-139.

Silliman, C. C., Elzi, D. J., Ambruso, D. R., Musters, R. J., Hamiel, C., Harbeck, R. J., Paterson, A. J., Bjornsen, A. J., Wyman, T. H., Kelher, M., England, K. M., McLaughlin-Malaxecheberria, N., Barnett, C. C., Aiboshi, J. and Bannerjee, A. (2003). Lysophosphatidylcholines prime the NADPH oxidase 
and stimulate multiple neutrophil functions through changes in cytosolic calcium. J Leukoc Biol. 73(4), 511-524.

Taylor, L. A., Arends, J., Hodina, A. K., Unger, C. and Massing, U. (2007). Plasma lyso-phosphatidylcholine concentration is decreased in cancer patients with weight loss and activated inflammatory status. Lipids in health and disease. 6, 17.

Weber, C., Erl, W. and Weber, P. C. (1995). Enhancement of monocyte adhesion to endothelial cells by oxidatively modified low-density lipoprotein is mediated by activation of CD11b. Biochem Biophys Res Commun. 206(2), 621-628.

Weng, Z., Fluckiger, A. C., Nisitani, S., Wahl, M. I., Le, L. Q., Hunter, C. A., Fernal, A. A., Le Beau, M. M. and Witte, O. N. (1998). A DNA damage and stress inducible $G$ protein-coupled receptor blocks cells in G2/M. Proc Natl Acad Sci U S A. 95(21), 12334-12339.

Wilson-Ashworth, H. A., Judd, A. M., Law, R. M., Freestone, B. D., Taylor, S., Mizukawa, M. K., Cromar, K. R., Sudweeks, S. and Bell, J. D. (2004). Formation of transient non-protein calcium pores by lysophospholipids in S49 Lymphoma cells. $J$ Membr Biol. 200(1), 25-33.

Wyman, T. H., Bjornsen, A. J., Elzi, D. J., Smith, C. W., England, K. M., Kelher, M. and Silliman, C. C. (2002). A two-insult in vitro model of PMN-mediated pulmonary endothelial damage: requirements for adherence and chemokine release. $\mathrm{Am}$ J Physiol Cell Physiol. 283(6), C1592-1603.

Yamamoto, M., Hara, H. and Adachi, T. (2002). The expression of extracellular-superoxide dismutase is increased by lysophosphatidylcholine in human monocytic U937 cells. Atherosclerosis. 163(2), 223-228.
Yamamoto, N. and Naraparaju, V. R. (1996). Role of vitamin D3binding protein in activation of mouse macrophages. $\mathrm{J}$ Immunol. 157(4), 1744-1749.

Yan, J. J., Jung, J. S., Lee, J. E., Lee, J., Huh, S. O., Kim, H. S., Jung, K. C., Cho, J. Y., Nam, J. S., Suh, H. W., Kim, Y. H. and Song, D. K. (2004). Therapeutic effects of lysophosphatidylcholine in experimental sepsis. Nat Med. 10(2), 161-167.

Yang, L. V., Radu, C. G., Wang, L., Riedinger, M. and Witte, O. N. (2005). Gi-independent macrophage chemotaxis to lysophosphatidylcholine via the immunoregulatory GPCR G2A. Blood. 105(3), 1127-1134.

Yuan, Y., Schoenwaelder, S. M., Salem, H. H. and Jackson, S. P. (1996). The bioactive phospholipid, lysophosphatidylcholine, induces cellular effects via G-protein-dependent activation of adenylyl cyclase. J Biol Chem. 271(43), 27090-27098.

Yun, M. R., Okajima, F. and Im, D. S. (2004). The action mode of lysophosphatidylcholine in human monocytes. J Pharmacol Sci. 94(1), 45-50.

Zhu, X., Learoyd, J., Butt, S., Zhu, L., Usatyuk, P. V., Natarajan, V., Munoz, N. M. and Leff, A. R. (2007). Regulation of eosinophil adhesion by lysophosphatidylcholine via a non-storeoperated Ca2+ channel. Am J Respir Cell Mol Biol. 36(5), 585-593.

Zurgil, N., Afrimzon, E., Shafran, Y., Shovman, O., Gilburd, B., Brikman, H., Shoenfeld, Y. and Deutsch, M. (2007). Lymphocyte resistance to lysophosphatidylcholine mediated apoptosis in atherosclerosis. Atherosclerosis. 190(1), 73-83. 